\title{
Tacit Knowledge Transfer in Australian Universities: Exploring the Barriers and Enablers
}

\author{
Ritesh Chugh, ${ }^{1, *}$ \\ ${ }^{1}$ Central Queensland University, School of Engineering and Technology, Melbourne 3000, Australia
}

\begin{abstract}
As organisational knowledge is greatly dependant on the tacit knowledge that its employees possess, it is important to pursue strategies that encourage sharing of employees' tacit knowledge. However, tacit knowledge sharing can be better promoted by understanding the barriers and enablers of tacit knowledge transfer. As universities are seen as the flag-bearers of knowledge creation and dissemination, this paper focuses on identifying the barriers and enablers of tacit knowledge transfer in universities. A qualitative research method was utilised for this study in which interviews of academics from four Australian universities were carried out. The reporting of data is based on a structured interpretative approach drawing demonstrative examples from the interview transcripts. The findings suggest that human, social and culture factors are addressed to ensure successful transfer of tacit knowledge. For effective transfer of tacit knowledge, universities need to create conditions that strengthen the enablers and suppress the barriers. Keywords: Education, Australian Universities, Tacit Knowledge Transfer
\end{abstract}

\section{Introduction}

Much of the knowledge required to succeed in realworld tasks is tacit in nature [1]. Tacit knowledge focuses on 'knowing how' rather than 'knowing that' [2]. However, in reality there is an overlap between 'how' and 'that'. An individual needs to know a task (skillset) to be able to articulate and transfer it. The transfer of tacit knowledge is important for all types and sizes of organisations so that skills, expertise and experience of its employees are shared and passed throughout the organisation, than just being retained by the employees who possess it. The use of knowledge in organisations can attribute to improvements in organisational processes and is a key element in creating and sustaining competitive advantage[3]. As organisational knowledge is greatly dependent on the tacit knowledge that its employees possess, it is important to pursue strategies that encourage sharing of employees' knowledge. Sharing of information between employees creates a more knowledgeable workforce [4]. Job performance is also enhanced through the sharing of knowledge and experience with colleagues [5].

Tacit knowledge is repeatedly acknowledged as an intangible resource [6], which implies that it does not have a physical presence whereas on the other end explicit knowledge is tangible and has a physical presence. Knowledge exists in both explicit (tangible) and tacit (intangible) forms. It is the intangible nature of tacit knowledge that makes it difficult to transmit and store. Tacit knowledge is difficult to access and transfer [7] but it is possible to convert tacit knowledge into explicit [8]. Since tacit knowledge is intuitive and practice-based, it is both valuable and difficult to transfer [9]. It is crucial that organisations identify where tacit knowledge is located so that it can be easily transferred. More importantly, an assessment of the barriers and enablers should be carried out to contribute to greater tacit knowledge transfer [10].

From a tacit knowledge sharing perspective in an organisational context, there are two evident problems, firstly sharing is difficult [11] and secondly, a restrictive knowledge-sharing culture [12]. Tacit knowledge, which is embedded in the minds of employees, is difficult to transfer. Moreover, even if these employees are willing to part with their tacit knowledge, there are barriers of tacit knowledge transfer in the universities context. In the case of universities, most tacit knowledge is located within its academic and research employees. In universities, an aspect of knowledge transfer would imply the sharing of work-related knowledge and expertise by academics with their peers within the university [13]. Therefore, university academics form the primary source of data for this research.

There is an apparent lack of understanding of the barriers and enablers that affect knowledge sharing [14]. Most previous research has predominantly focussed on knowledge sharing in the corporate sector disregarding higher education institutions [15] and knowledge sharing behaviour should be studied in universities globally [16]. This study plugs that scarcity gap by not just focussing on knowledge sharing but specifically on tacit knowledge transfer in the universities' context, from the perspective of Australian university academics. Moreover, universities are considered as the formal means of creating, disseminating and transferring knowledge [17]. As the problem lies in the difficulty of transferring tacit knowledge, this study sets out to explore the enablers and barriers of tacit knowledge

* Corresponding author: r.chugh@,cqu.edu.au 
transfer, specifically from the viewpoint of Australian university academics.

The next section provides a brief review of the previous literature. This is followed by the research method in section three, which outlines the merits of the adopted qualitative approach. Section four then outlines the findings, along with a discussion. Finally, the last section of the paper summarises the conclusion, outlines limitations and avenues for future research.

\section{Literature Review}

Tacit knowledge comprises of the skills, ideas and experiences people possess, which are hard to access and transfer [18]. Tacit knowledge is difficult to articulate in an explicit form. Nonaka, Toyama and Konno [19] suggest that explicit knowledge can be expressed in a formal and systematic language and is easily shared whereas tacit knowledge is personal and includes subjective insights, intuitions and hunches. Tacit knowledge develops thorough practice as people engage in day-to-day activities whether at work or home. These day-to-day activities provide experience and develop different types of skills.

Nonaka [8] has argued that knowledge can only exist at the level of the individual, so it becomes really important to use the knowledge individuals possess. Apart from using their tacit knowledge, the means of making that personal knowledge available for reuse via knowledge transfer is important. Tacit knowledge can be transferred from an individual into a separate object in the form of something tangible such as a standard operating procedure or lessons learnt document, or it can be shared through seminars or story telling activities.

The terms knowledge sharing and knowledge transfer are sometimes used synonymously but the difference between them is blurry [20]. In this paper too, at times, these terms have been used interchangeably. A definition of knowledge transfer is "the focused, unidirectional communication of knowledge between individuals, groups, or organizations such that the recipient of knowledge (a) has a cognitive understanding, (b) has the ability to apply the knowledge, or (c) applies the knowledge." [21], pg. 542.

The factors that adversely affect the success of knowledge management implementation are classified as knowledge management barriers [22]. However, knowledge management is a large discipline and looking at implementation and knowledge management under one lens would only provide a siloed picture. The importance of knowledge sharing cannot be underscored. Riege [12] has provided an extensive list of knowledge sharing barriers from a variety of different perspectives, however has cautioned that knowledge sharing barriers will vary greatly amongst different organisations. Reige (ibid) has also highlighted that the first step in successful knowledge sharing is the identification of knowledge sharing barriers.

Barriers to knowledge transfer can be defined as factors due to which knowledge transfer does not take place [23]. Barriers that thwart knowledge management efforts have been identified by various authors [12];[22];[24] but there is a clear lack of emphasis on tacit knowledge transfer barriers. Identifying and amalgamating barriers to knowledge transfer does not necessarily lead to a segregation between tacit and explicit knowledge transfer barriers. Both tacit and explicit knowledge transfer barriers should be looked in isolation to each other. Polanyi [25] justifies that tacit and explicit knowledge are separate and distinct and hence need to be treated differently. There has been a call to specifically identify the barriers to tacit knowledge transfer in the universities context [26].

Any knowledge management strategy needs three inter-related elements to operate effectively - people, processes and technology [17]. More specifically, a tacit knowledge management strategy is needed because tacit knowledge is unique, gives a competitive advantage and provides support [27]. Knowledge management has been widely explored in the corporate business sector, but universities are lagging behind [28]. Undoubtedly, the transfer of tacit knowledge is a challenging task because of the very sticky nature of tacit knowledge. To exacerbate the issue, transfer of teachers' tacit knowledge is a difficult point in the overall knowledge management efforts of universities [29]. Universities are knowledge hubs where knowledge creation and knowledge sharing takes place and removing hierarchical barriers will improve tacit knowledge capacity and increase innovation [30]. It is essential to create a favourable environment with the right conditions for the spread, transformation, creation and application of tacit knowledge [29]. These right conditions can be termed as the enablers.

The literature points to the importance of tacit knowledge sharing. Researchers from different disciplines have attempted to approach the field of knowledge from different views [31];[32];[33]. Many of these researchers rest on the objective view and tend to privilege explicit over tacit knowledge [34]. Despite the progress that has been made in understanding the nature of explicit knowledge, little has been done to explore the transfer of tacit knowledge especially by academics in universities in Australia. The current understanding of the nature of tacit knowledge and its implications for universities is still far from satisfactory. This study will reveal the barriers and enablers of tacit knowledge transfer in Australian universities. An insight into the barriers and enablers of knowledge sharing will pave the way for providing a significant advantage for organizations [35], particularly universities.

\section{Research method}

A qualitative research method, in the form of interviews, was used for this study. Qualitative research is usually unstructured, more explorative and emphasises understanding and gaining insights [36]. In an attempt to gain a more accurate and clear picture of the interviewee's stance in an unrestricted environment, indepth structured interviews were conducted to uncover enablers and barriers of tacit knowledge transfer. 
Qualitative interviews can be used to gain in-depth information about the interviewees' thoughts, beliefs, knowledge, reasoning, motivations and feelings [37]. This research primarily conducted qualitative structured interviews using a predetermined list of open-ended questions and each research subject was asked exactly the same questions in exactly the same order [38]. The study took place using academics from four Australian public universities as the main sample as they deal with tacit knowledge on a daily basis. Teachers are the foremost illustration of knowledge workers [39] as they are involved in tacit knowledge creation, distribution and application.

The interviewee profile considered ideal for the interviews was a lecturer or senior lecturer and an associate professor or professor from each university, thus providing a stratified purposeful sample. Eight interviews were carried out in total with two academics from each of the four universities. Qualitative research focusses on a broad sample that can be interviewed deeply to ensure important aspects and variations of the phenomenon being studied are captured in the sample, regardless of whether the sample size is 8 or 100 [40]. In terms of the sample size $(n=8)$, it was also considered justified as the interviewees have 'information power'. Information power indicates that the more information the sample holds, the lower is the number of interviewees required [41].

Although carried out as part of a larger previous study, the questions analysed in this paper represent an endeavour to identify the barriers and enablers of tacit knowledge sharing, with an ultimate aim to encourage tacit knowledge transfer. It was impossible to present the findings of the large study without dividing it into easily reportable chunks to provide greater meaning.

For the analysis, multiple iterations involved transcribing, reviewing the interview transcripts, and coding relevant information that was useful in investigating and reaching meaningful findings. The reporting of data is based on a structured interpretative approach drawing demonstrative examples from the interview transcripts. Verbatim quotes and extracts, in italics, from the interviews have been woven in the narrative analysis to demonstrate and support interpretation in the following section.

\section{Findings and discussion}

There are several barriers that make the transfer of tacit knowledge difficult. It is necessary to identify the barriers so that corrective action can be initiated. An interviewee illustrated differing barriers that deter the transfer of tacit knowledge 'Politics, mind sets, personalities' to name a few. Other barriers that were identified by another interviewee were 'Lack of leadership, and lack of knowledge management technology in the university'. Communication was high on the list of barriers that most interviewees provided. One of the interviewee remarked that communication issues, and cultural issues - personal - culture of the person and the organisational culture both. The person who is coming from a different background who's not willing to share on the forums, if we go for coffee he will share more than writing which is available to public.' It is evident from this comment that providing an informal means of communication may be more suitable to tacit knowledge transfer rather than strictly formalising it or making it mandatory. Inefficient communication has been cited as a barrier to knowledge management [24] and knowledge sharing cannot be instructed or forced but can be nurtured by providing a facilitative environment [16].

An interviewee who identified culture as a barrier remarked that 'on this campus, we have different background people. Again, that's my-we have different agenda only in people's mind. It could be an advantage, it could be a barrier but, again, if the culture is correct, barrier could become an incentive. So different ways, two sides of the coin.' This implies that if universities cultivated the right sharing culture, it could actually be an incentive and academics would be more willing to share. Creating a knowledge-sharing culture is an important enabler of enhancing knowledge sharing [42].

Another barrier was the lack of interest and peer trust in tacit knowledge sharing that was resonated by an interviewee in the comment that some staff are not interested in my ideas, my intentions may be misinterpreted as criticism.' Moving away from these personal characteristics, an interviewee identified ' $J o b$ insecurity as another one' Work overload was also cited as a barrier by an interviewee who stated that 'people are often too tired and overburdened with admin and bureaucracy to engage in meaningful sharing and reflection.' Another interviewee remarked that 'Realistically, we are overloaded with work and the flow of information. This can often prevent sharing of ideas, experiences and skills because you need to prioritise your work and the basics (research, teaching, administration) take precedence.' In fact the issue of high staff workload being a barrier was cited a number of times by various interviewees.

Bean counting or counting everything is seen as being detrimental to tacit knowledge transfer. The problem with bean counting is that it solely comes down to profit and loss and neglects the people aspect. One of the interviewee exemplified that 'the barrier is this: everything bean-counted - bean-counting mechanism is the basic barrier. Every time you are doing something you are thinking - am I fulfilling - am I ticking a box or not? And most people are just coping with the ticking the boxes. The answer is we are academics, we do not separate between week day and weekend and then we're a sliding scale - you do more work on the weekday, less on weekend - but you can't turn yourself off and if you do, then you're not an academic. So as soon as you even start thinking that as an academic we only work five days a week, it's contrary to being an academic'. Academics have echoed a conscientious notion that tacit knowledge transfer should not be made mandatory otherwise it will lead to a further decline in tacit knowledge transfer rather than encouraging it. In fact to make it work, more incentives need to be provided. 
Table 1. Barriers of tacit knowledge transfer

\begin{tabular}{|l|}
\hline \multicolumn{1}{|c|}{ Barriers } \\
\hline$\bullet$ Inadequate communication \\
\hline$\bullet$ Lack of avenues for informal interaction \\
\hline$\bullet$ Culture - personal and organisational \\
\hline$\bullet$ Lack of peer trust \\
\hline$\bullet$ Job insecurity \\
\hline$\bullet$ Work overload \\
\hline$\bullet$ Lack of resources and incentives \\
\hline$\bullet$ Lack of leadership \\
\hline$\bullet$ Organisational politics \\
\hline$\bullet$ Lack of technology \\
\hline
\end{tabular}

Table 1 outlines the barriers that were identified from the interviews. It is imperative that the identified barriers are eliminated or at least reduced so that tacit knowledge transfer can take place effectively. To support this claim an interviewee very appropriately commented that ' $I$ guess if all the barriers I mentioned could be turned into - really examined or turned to the table around, that would be a way of capturing the tacit knowledge'. However, the interviewees also specifically identified various enablers that can aid the transfer of tacit knowledge.

One of the interviewee remarked that it is important to 'create an atmosphere of encouraging people' so that tacit knowledge transfer can take place. This interviewee also focussed on the need to create more avenues for informal sharing. The interviewee said that 'I actually personally enjoy the coffee room for knowledge sharing we help each other, advise each other, so I think it's just great. There's no bossing in there - we are all equal and that's just the kind of environment probably - very good.' This demonstrates a good example of collegiality in an informal environment. Informal settings such as social events and coffee breaks provide a good place for knowledge sharing although more knowledge sharing appears to take place in formal settings than in informal settings [43].

Quite a few interviewees focussed on the provision of more resources so that tacit knowledge transfer could take place. An interviewee remarked that the rules of the resource allocation right from the top is not conducive of tacit knowledge transfer at all.' Apart from monetary resources, lack of time was another concern. An interviewee commented on the reason for not engaging in sharing knowledge was that 'Without sufficient time, with fulltime teaching and part time researching, sharing my ideas, experiences and skills are not on my priority list. I am struggling to have sufficient time to teaching and research on everyday basis.' Time as a prohibiting factor was definitely very high on the responses provided by the interviewees. Another interviewee said that 'There is absolutely no time provided. Everything we do is on top of our other duties.' An interviewee added that 'I teach between 12 and 15 hours per week (including online offshore student teaching). This drains personal energy and provides little opportunity or motivation to reflect and share ideas, experiences and skills.' The lack of time was a common problem and hence to enable the transfer of tacit knowledge, senior management should look into this issue and explore how staff can be encouraged to share tacit knowledge. A fine line between the economics of academics' day-to-day operations and sharing of knowledge can only be achieved if some sort of time-release is provided. Some excerpts from the interviewees about a reduction in teaching time so that more time for tacit knowledge transfer is available: 'reduce teaching related load so that I can have time to do other things.', 'Reduce teaching load', 'create time for such activities' and 'free time to focus on information transfer'. Human and social factors should be considered and adequately addressed for tacit knowledge transfer to take place successfully [44].

Cultivating a culture that encourages and promotes tacit knowledge sharing is also critical. One of the interviewee's commented that 'there's a challenge in tempering someone's tacit understanding in a culturally contextual sort of environment.' It is this sort of challenge that senior managers need to reduce so that the university environment can become more conducive to knowledge sharing. Another interview stated that 'cultivate a sharing culture, it's a good way to start with.' Yet another interviewee focussed upon the importance of an open culture by saying that develop a knowledge sharing culture, so that people come forward and share their good and maybe sometimes bad experience. A learning organisation is one that allows people to take risks.' An interviewee said that 'culture of blame, fear of failure, putting people down in public meetings' are not conducive to sharing ideas, experiences and skills within any university. Another interviewee exemplified that the bureaucratic mindsets and often controlling culture operates antithetically in regard to the notion of building social capital in dynamic and boundaried interfaces and spaces where new paradigms, ideas and solutions might emerge. Control and standardisation can be inhibitive concerning creative thought and sharing ideas'. This comment also aligns with the notion of too much control from senior management as being a prohibitive factor in tacit knowledge sharing. An interviewee commented that 'cultural change often needed lead by management encouraging the sharing of ideas.' Hence a cultural shift is required which needs to be promoted by top management. Developing a knowledge sharing culture is possible but that can be a difficult and time consuming process [45]. Pan and Scarborough [45] have emphasised that senior management play an important role in bringing about and facilitating a cultural change. Senior management plays an important role because their behaviour influences that of people working under them. Senior management who exhibit positive leadership traits can motivate their team and have a positive impact on enhancing organisational performance. An interviewee stated that 'motivate people to make people realise how tacit knowledge is so important.' Knowledge sharing can be enhanced by developing motivational drivers that are aligned with willingness of employees to share knowledge [16]. 
Senior management's commitment in enabling the transfer of tacit knowledge is important. The role of senior management is very crucial in ensuring that staff understand the importance of tacit knowledge transfer. Apart from that, the funding for such activities to take place has to come from senior management. An interviewee remarked that I would have the topmanagement to announce formally and encourage the sharing.' Knowledge worker retention is also enhanced when an organisation cultivates an active learning culture, its human resource program and practices support knowledge management initiatives and its senior management supports and understands the importance of knowledge management [46]. This also leads to an important factor of developing a learning culture that promotes and supports innovation, creativity and risk taking rather than admonish it.

Technology has also been identified as an enabler of tacit knowledge sharing by multiple interviewees who see Information and Communication Technologies (ICT) playing an important role in capturing, sharing and applying tacit knowledge. An interviewee focussed on developing expertise finder directories that they could set that up so it's sort of a knowledge bank of saying these are the topics that people have the skills in.' Expertise finder directories are already available at most universities. It can be argued that easy access to academic staffs' expertise does not necessarily translate to a knowledge sharing culture. It may, though, help.

The role of technology in promoting the transfer of tacit knowledge is vital. However, academics must take the first step in trying to document their knowledge. Then, IT staff must find a way of indexing and structuring the codified knowledge so that it is easily accessible. The stored codified knowledge is of little use if employees are not willing to search for this knowledge when required [47]. Alternatively universities can adopt push systems where the codified knowledge is pushed out to employees rather than waiting for them to pull it. It can be argued that a push-based system may not be favoured as it can be intrusive and employees may not need the information at that instant. A searchable repository of academics' expertise and know-how can also be seen as a starting step towards knowledge sharing - once tacit knowledge is codified, it becomes, easy to transfer and share between other employees through the use of ICT. Table 2 outlines the enablers that were identified from the interviews.

Table 2. Enablers of tacit knowledge transfer

\begin{tabular}{|l|}
\hline \multicolumn{2}{|c|}{ Enablers } \\
\hline $\begin{array}{l}\text { Encourage open communication (both } \\
\text { formal and informal) }\end{array}$ \\
\hline $\begin{array}{l}\text { Provide adequate resources (time and } \\
\text { monetary) }\end{array}$ \\
\hline - Cultivate a knowledge sharing culture \\
\hline - Senior management commitment \\
\hline - Promote openness and trust \\
\hline - Introduce technology \\
\hline
\end{tabular}

\begin{tabular}{|l|}
\hline - Provide incentives \\
\hline - Provide job stability/security \\
\hline - Reduce organisational politics \\
\hline
\end{tabular}

It is important to highlight that 'the opposite of a knowledge-sharing enabler often also exists as a barrier' [48], pg. 56. The existence of some of the identified issues can be seen as a barrier or an enabler depending upon the context. For any successful tacit knowledge transfer initiative in an organisation, it is vital that the identified human, social and culture factors are tackled to ensure success. However, all organisational initiatives towards tacit knowledge sharing will be futile if employees are not motivated to share. Employees' willingness to share will depend upon their perception of the pros and cons of sharing knowledge. If the sharing of tacit knowledge does not produce any benefits for the employees themselves, the reluctance will be higher and vice-versa.

\section{Conclusion}

The ephemeral and elusive nature of tacit knowledge makes it more important to be captured and shared with others. The strength of this qualitative study lies in its assessment of barriers and enablers of tacit knowledge transfer and translates into what universities can do to encourage tacit knowledge transfer. Through the use of a qualitative method, the study provides empirical evidence. The results of this research highlight the barriers that need to be addressed and areas where universities need to make improvements in order to encourage and facilitate tacit knowledge sharing. It focuses attention on important areas that are often neglected but are significant for tacit knowledge transfer.

The results from the study suggest that the transfer of tacit knowledge transfer in Australian universities is often hampered by inadequate communication, lack of avenues for informal interactions, culture (personal and organisational), lack of peer trust, job insecurity, work overload, lack of resources and incentives, lack of leadership, organisational politics and lack of technology. On the other hand, the enablers constitute encouraging open formal and informal communication, providing adequate resources, cultivating a knowledge sharing culture, senior management commitment, promoting openness and trust, introducing technology, encouraging documentation, providing incentives and job security and reducing organisational politics.

The findings have implications for researchers and practitioners. The complex nature of tacit knowledge transfer challenges every organisation and different approaches to retain and transfer tacit knowledge have been attempted in practice with varying levels of success and failure. This study contributes to the literature by providing a more integrative view of various tacit knowledge transfer enablers and barriers; as both driven by individuals (academics) and the expectations of workplaces (universities). Since knowledge is often embedded in practice, the practices or processes adopted 
by academics and the tacit knowledge they possess is localised and context specific. It is becoming very necessary that universities make all attempts to convert tacit knowledge to explicit. In order to enhance any university's performance, it is crucial that the knowledge, skills and experience of staff are retained. However, implementation of tacit knowledge sharing practices should be seen as only the first step in an evolving management process that will eventually include more formal and systematic practices.

For greater transfer of tacit knowledge, universities need to create conditions that strengthen the enablers and suppress the barriers. The identified enablers may require considerable monetary investments especially if staff teaching loads are varied so that tacit knowledge transfer can take place. It really is a predicament since currently most universities are at doldrums to reduce their spending. However, it is crucial that universities acknowledge the value of their intellectual capital and develop channels that allow the transfer of tacit knowledge. There is no doubt that to usher such a tacit knowledge sharing attitude organisationally would require significant investment in resources from different levels of a university. Any direction that universities will take will require some level of experimentation to see what works best for them. A one-size-fits-all shoe may not be suitable.

As can be expected, the study has some limitations. The sample consists of academics from universities. Hence, the findings of this study may not be generalisable across other sectors. In addition, as the findings pertain to only Australian universities, the results may be valid in developed countries but may not be generalisable to developing countries with a different culture. It would also be inappropriate to generalise the findings to a larger population of academics or other Australian universities too due to the small sample. Moreover, qualitative research has its own natural limitation and is not proposed to be used for generalising across a larger population. However, this explorative study paints a picture of the reality from the ground. Future studies can address these limitations and more specifically, it would also be valuable to study tacit knowledge transfer specifically at the senior management level of universities.

\section{References}

1. R. J. Sternberg and J. A. Horvath, Tacit knowledge in professional practice: Researcher and practitioner perspectives. Psychology Press, (1999).

2. R. J. Sternberg, G. Forsythe, J. Hedlund, J. Horvath, R. Wagner, W. Williams, S. Snook and E. Grigorenko, Practical intelligence in everyday life. Cambridge University Press, (2000).

3. D. Teece, Future directions for KM, California Management Review, 40 (3), 123-126 (1998).
4. T. Peariasamy and N. N. A. Mansor, On-the-job knowledge sharing: how to train employees to share job knowledge, Jurnal Kemanusiaan, 6 (2) (2017).

5. R. e. Masa'deh, R. Shannak, M. Maqableh and A. Tarhini, The impact of knowledge management on job performance in higher education: The case of the University of Jordan, Journal of Enterprise Information Management, 30 (2), 244-262 (2016).

6. R. Jacobson, Unobservable effects and business performance, Marketing Science, 9 (1), 74-85 (1990).

7. S. O. Syed-Ikhsan and F. Rowland, Knowledge management in a public organization: a study on the relationship between organizational elements and the performance of knowledge transfer, Journal of Knowledge Management, 8 (2), 95-111 (2004).

8. I. Nonaka, A dynamic theory of organizational knowledge creation, Organization Science, 5 (1), 14-37 (1994).

9. M. Stover, Making tacit knowledge explicit: The ready reference database as codified knowledge, Reference Services Review, 32 (2), 164-173 (2004).

10. T. Foos, G. Schum and S. Rothenberg, Tacit knowledge transfer and the knowledge disconnect, Journal of Knowledge Management, 10 (1), 6-18 (2006).

11. H. S. Shim and G. L. Roth, Sharing tacit knowledge among expert teaching professors and mentees: Considerations for career and technical education teacher educators, Journal of Industrial Teacher Education, 44, 5-28 (2007).

12. A. Riege, Three-dozen knowledge-sharing barriers managers must consider, Journal of Knowledge Management, 9 (3), 18-35 (2005).

13. T. Ramayah, J. A. Yeap and J. Ignatius, Assessing knowledge sharing among academics: A validation of the knowledge sharing behavior scale (KSBS), Evaluation Review, 38 (2), 160-187 (2014).

14. P. Hendriks, Why share knowledge? The influence of ICT on the motivation for knowledge sharing, Knowledge and process management, 6 (2), 91-100 (1999).

15. N. A. M. Ismail, M. X. Xu, M. Wood and C. Welch, To share or not to share? Research-knowledge sharing in higher education institution: preliminary results, International Journal of Information Technology and Management, 12 (3-4), 169-188 (2013).

16. M. Hassan, I. Aksel, M. S. Nawaz and S. Shaukat, Knowledge sharing behavior of business teachers of Pakistani universities: An Empirical Testing Of Theory Of Planned Behavior, European Scientific Journal, 12 (13), 29-40 (2016).

17. L. Trivella and N. K. Dimitrios, Knowledge management strategy within the higher education. The case of Greece, Procedia-Social and Behavioral Sciences, 175, 488-495 (2015).

18. R. Chugh, Do Australian universities encourage tacit knowledge transfer?, presented at the 7th International Joint Conference on Knowledge Discovery, Knowledge Engineering and Knowledge Management, 128-135 (2015). 
19. I. Nonaka, R. Toyama and N. Konno, SECI, Ba and leadership: a unified model of dynamic knowledge creation, Long Range Planning, 33 (1), 5-34 (2000).

20. D. Paulin and K. Suneson, Knowledge transfer, knowledge sharing and knowledge barriers-three blurry terms in KM, The Electronic Journal of Knowledge Management, 10 (1), 81-91 (2012).

21. W. R. King, in Encyclopedia of Knowledge Management, edited by D. Schwartz IGI Global, pp. 538-543 (2006).

22. M. Singh and R. Kant, Knowledge management barriers: An interpretive structural modeling approach, International Journal of Management Science and Engineering Management, 3 (2), 141-150 (2008).

23. G. Szulanski, Sticky knowledge: Barriers to knowing in the firm. Sage, (2002).

24. F. Lotti Oliva, Knowledge management barriers, practices and maturity model, Journal of Knowledge Management, 18 (6), 1053-1074 (2014).

25. M. Polanyi, The Tacit Dimension. M. E. Sharp Inc, New York, (1966).

26. R. Chugh, S. Wibowo and S. Grandhi, Mandating the transfer of tacit knowledge in Australian universities, Journal of Organizational Knowledge Management, 2015, 1-10 (2015).

27. H. Wright, Tacit Knowledge and pedagogy at UK Universities: Challenges for effective management, Electronic Journal of Knowledge Management, 6 (1) (2008).

28. A. I. Ojo, Knowledge management in Nigerian universities: A conceptual model, Interdisciplinary Journal of Information, Knowledge, and Management, 11, 331-345 (2016).

29. L. Zhang and Z. Han, Analysis on the management of College teachers' tacit knowledge, International Education Studies, 1 (3), 21-24 (2008).

30. T. Kaya and B. Erkut, The tacit knowledge capacity of lecturers: A cross-country comparison, presented at the European Conference on Knowledge Management,437 (2016).

31. H. Benbya, G. Passiante and N. A. Belbaly, Corporate portal: a tool for knowledge management synchronization, International Journal of Information Management, 24 (3), 201-220 (2004).

32. N. K. Kakabadse, A. Kakabadse and A. Kouzmin, Reviewing the knowledge management literature: towards a taxonomy, Journal of Knowledge Management, 7 (4), 75-91 (2003).

33. N. Prat, in Encyclopedia of Knowledge Management, edited by D. Schwartz (Idea Group Reference, Hershey, PA, pp. 848-854 (2011).

34. S. D. Cook and J. S. Brown, Bridging epistemologies: The generative dance between organizational knowledge and organizational knowing, Organization science, 10 (4), 381-400 (1999).

35. M. Asrar-ul-Haq and S. Anwar, A systematic review of knowledge management and knowledge sharing: Trends, issues, and challenges, Cogent Business \& Management, 3 (1), 1-17 (2016).

36. P. N. Ghauri and K. Grønhaug, Research methods in business studies: A practical guide. Pearson Education, (2005).
37. B. Johnson and L. Christensen, Educational research: Quantitative, qualitative, and mixed approaches. Sage, (2008).

38. V. Minichiello, R. Aroni, E. Timewell and L. Alexander, Melbourne: Longman Cheshire (1990).

39. J. Cortada, Rise of the knowledge worker. Routledge, (2009).

40. R. Elliott and L. Timulak, Descriptive and interpretive approaches to qualitative research, A handbook of research methods for clinical and health psychology, 1, 147-159 (2005).

41. K. Malterud, V. D. Siersma and A. D. Guassora, Sample size in qualitative interview studies: guided by information power, Qualitative health research, 26 (13), 1753-1760 (2016).

42. T. H. Davenport and L. Prusak, Working knowledge: How organizations manage what they know. Harvard Business Press, Boston, MA, (1998).

43. I. Reychav and D. Te'eni, Knowledge exchange in the shrines of knowledge: The "how's" and "where's" of knowledge sharing processes, Computers \& Education, 53 (4), 1266-1277 (2009).

44. S. Panahi, S. Panahi, J. Watson, J. Watson, H. Partridge and H. Partridge, Conceptualising social media support for tacit knowledge sharing: physicians' perspectives and experiences, Journal of Knowledge Management, 20 (2), 344-363 (2016).

45. S. L. Pan and H. Scarbrough, Knowledge management in practice: An exploratory case study, Technology Analysis \& Strategic Management, 11 (3), 359-374 (1999).

46. L.-A. Ho, What affects organizational performance? The linking of learning and knowledge management, Industrial Management \& Data Systems, 108 (9), 1234-1254 (2008).

47. G.-W. Bock, A. Kankanhalli and S. Sharma, Are norms enough? The role of collaborative norms in promoting organizational knowledge seeking, European Journal of Information Systems, 15 (4), 357367 (2006).

48. A.-M. Lilleoere and E. Holme Hansen, Knowledge-sharing enablers and barriers in pharmaceutical research and development, Journal of Knowledge Management, 15 (1), 53-70 (2011). 